Original Research Paper

\title{
Non-Alcoholic, Naturally-Carbonated Beverage from Vitis Vinifera Using Saccharomyces Cerevisae Isolated from Cheese Whey
}

\author{
Heena Chilana, Sanju Arora, Robinka Khajuria and Loveleen Kaur \\ School of Biotechnology and Biosciences, Lovely Professional University, Phagwara-144401, Punjab, India
}

\author{
Article history \\ Received: 21-01-2015 \\ Revised: 30-04-2015 \\ Accepted: 10-06-2015 \\ Corresponding Author: \\ Loveleen Kaur \\ School of Biotechnology and \\ Biosciences, Lovely \\ Professional University, \\ Phagwara-144401, Punjab, \\ India \\ Email: loveleensays@gmail.com
}

\begin{abstract}
In the present work a pure yeast culture was isolated from cheese whey and identified by $26 \mathrm{~S}$ rDNA sequencing as Saccharomyces cerevisiae NRRL Y-12632. This yeast was used to produce low alcoholic self carbonated beverage from grape juice, grape: Kinnow juice $(2: 1)$ and grape: Pomegranate juice (2:1) under optimized conditions. The physicochemical properties of 3 days fermented grape: Pomegranate beverage $(2: 1)$ were $\mathrm{pH}$ 3.87, TSS $15^{\circ} \mathrm{B}, \mathrm{CO}_{2}$ content 0.09 bar, acidity $0.24 \%$, sugar-acid ratio $63.34 \%$ and alcohol $0.06 \%(\mathrm{v} / \mathrm{v})$. The changes in the physicochemical properties recorded were $\mathrm{pH} 3.08$, TSS $14.8^{\circ} \mathrm{B}, \mathrm{CO}_{2}$ content 0.14 bar, acidity $0.35 \%$, sugar-acid ratio $42.04 \%$ and alcohol $0.10 \%(\mathrm{v} / \mathrm{v})$ after storage for 30 days at $4{ }^{\circ} \mathrm{C}$ without adding any preservative. Among the four beverages, grape: Pomegranate beverage (2:1) was highly acceptable when compared on 9 point hedonic scale. Naturally produced $\mathrm{CO}_{2}$ was found to give tangy taste to the beverage along with antimicrobial properties. This technology can be a useful processing technology for perishable fruits and vegetables and can also help to overcome their seasonal overabundance.
\end{abstract}

Keywords: Beverage, Low Alcoholic, Physicochemical Properties, Self Carbonated, Yeast

\section{Introduction}

Fermented and non fermented beverage produced from different fruits and vegetable have been gaining popularity with the general masses. The growing demand of such products can be catered to by using seasonal fruits for the production of these beverages. Being perishable commodities, these fruits need to be processed in order to avoid their wastage due to seasonal glut. According to Kaur et al. (2014), in India only, the cumulative vegetable and fruit wastage ranges from 5.8 to $18 \%$ of the total produce. In the current studies, a technology was developed for the production of naturally carbonated, non-alcoholic beverages from grapes. Grape (Vitis vinifera), a fruity berry of the woody deciduous plant belonging to the family Vitaceae contains a large amount of sugar (15 to $25 \%$ ), with roughly equal amounts of glucose, fructose, only traces of sucrose and vitamin $\mathrm{C}$ (around $3 \mathrm{mg} / 100 \mathrm{~g}$ ). Grapes are also known to contain quercetin, kaempferol, caffeic acid, p-coumaric acid, cinnamic acid, epicatechin and anthocyanidins which act as phytonutrients and help in curing many diseases in humans (Nile et al., 2013).
Fermentation of fruit juices such as grape juice adds to the nutritive value of the beverage as well as enhances the flavour and other desirable qualities associated with digestibility and edibility of food products (Kolawole et al., 2007). Yeasts play a central role in the fermentation of foods and beverages, with high carbohydrate content (Jimoh et al., 2012). Different yeast species are responsible for providing different concentration of alcohol, $\mathrm{CO}_{2}$, taste and fragrance to the beverage produced. According to the BCAP code of the United Kingdom, beverage containing less than $1.2 \%(\mathrm{v} / \mathrm{v})$ alcohol is considered as low-alcoholic while a beverage that contains less than $0.5 \%$ Alcohol By Volume (ABV) is considered to be non-alcoholic.

Additionally, various fruits, condiments, sweeteners etc can be used as flavour enhancers by blending the fruit juices during beverage production. Blending of juices for beverage production can be useful because along with increasing the flavours, these may also improves the nutritional value. In the present study grape juice was blended with pomegranate and kinnow juice. With general public becoming more conscious about the 
use of health foods, the current work aimed at the production of a carbonated beverage containing low alcohol content.

\section{Materials and Methods}

\section{Isolation of Yeast Isolates}

Different samples were used for isolation of best suited isolate of yeast for the production of non-alcoholic and high carbonated beverage from grape juice. The samples included tomato peel, resin, potato peel, sugarcane, lemon rind, berries, pineapple, cheese whey, carrot peel and orange rind. Appropriately diluted samples were spread plated on yeast peptone dextrose agar supplemented with Chloramphenicol and were incubated for 3 days at $27 \pm 1^{\circ} \mathrm{C}$. Colonies with distinct morphology were selected in order to obtain pure culture of microorganism.

\section{Screening Yeast Isolates}

Yeast cultures were screened on the basis of their potential to produce low amount of alcohol and high carbonation by inoculating all the isolates in the grape juice which was diluted with distilled water in the ratio of $2: 1$. Grape juice after dilution was pasteurized and brix adjusted to $16^{\circ} \mathrm{B}$. The juice was then inoculated with $0.5 \%(\mathrm{v} / \mathrm{v})$ inoculum in one litre pasteurised glass bottles band incubated at $27 \pm 1^{\circ} \mathrm{C}$ for $72 \mathrm{~h}$. Yeast isolate having the desired characteristics was further morphologically, biochemically and molecularly characterized.

\section{Morphological and Biochemical Characterization}

Morphological characterisation of the yeast isolate was carried out according to the methods of Guilliermond (2003) which takes into consideration colour, shape, surface, margin and colony elevation on Yeast Peptone Dextrose.Yeast isolates were then subjected to biochemical tests viz. fermentation of sugars (Ghinea et al., 2009), amylase production test (Fossi et al., 2009), urease test (Roberts et al., 1978) and acid production from glucose (Kurtzman et al., 2011).

\section{Molecular Characterization}

For molecular identification, genomic DNA (gDNA) of the isolate was isolated and fragment of $26 \mathrm{~S}$ rDNA gene was amplified by PCR from gDNA. Forward and reverse DNA sequencing reaction of PCR amplicon was carried out with DF and DR primers using BDT v3.1 Cycle sequencing kit on ABI 3730xl Genetic Analyzer. This 26S rDNA gene sequence was the used to carry out BLAST with the nrdatabase of NCBI GenBank database. Based on maximum identity score first ten sequences were selected and aligned using multiple alignment software program Clustal W. Distance matrix was generated using RDP database and the phylogenetic tree was constructed using MEGA 4.

\section{Production of Non-Alcoholic Naturally Carbonated Beverage}

\section{Preparation of Grape Juice and Blends}

Fresh, mature and healthy grapes, kinnows and pomegranates were purchased from the local retail market. Fruits were washed with chlorinated water and fruits with signs of defect were sorted out. Washed fruits were the used for extraction of juice using electronic juicer. The juices were filtered with muslin cloth to remove any pulp.

\section{Blending and Preparation of Grape Beverage}

Grape juice was blended separately with kinnow juice and pomegranate juice in the ratios of $1: 1,2: 1$ and $3: 1$. However, all the further experiments were carried out at 2:1 ratio since it was found during the earlier studies that $1: 1$ and $3: 1$ ratios of fruit juice with blends gave a bland taste or increased the sourness or bitterness of the fermented beverage (Kaur et al., 2014). Pure grape juice and blended grape juice were diluted in ratio 1:2 with distilled autoclaved water, pasteurized at $62.8^{\circ} \mathrm{C}$ for $30 \mathrm{~min}$ and rapidly cooled to ambient temperature $\left(25^{\circ} \mathrm{C}\right)$. Brix was adjusted to $15^{\circ} \mathrm{Bx}$ by adding pasteurized sugar solution $(500 \mathrm{~g} / \mathrm{L})$.

\section{Grape Beverage Fermentation}

About $24 \mathrm{~h}$ old yeast inoculum $(0.5 \%)$ was added to pure and blended juices. The inoculated juices were incubated at ambient temperature $\left(27 \pm 1^{\circ} \mathrm{C}\right)$ for $72 \mathrm{hrs}$. The beverage was then siphoned, bottled and stored in refrigerated conditions, according to method given by Jooyandeh (2013).

\section{Physico-Chemical Analysis}

Physicochemical analysis of beverages was carried out by calculating the $\mathrm{pH}$ (by digital $\mathrm{pH}$ meter), $\operatorname{TSS}\left({ }^{0} \mathrm{~B}\right)$ (by refractrometer $\left(0-32^{\circ} \mathrm{B}\right), \mathrm{CO}_{2}$ content by Burette Titration method, alcohol content (by potassium dichromate titration method) (Batac et al., 2012). Total acidity \% citric acid by Cunniff (1999) and sugar-acid ratio. These properties were assessed after 3days of fermentation and after 15 and 30 days of refrigeration Sensory evaluation of beverage was carried out using nine-point hedonic scale.

\section{Microbiological Assay of Fermented Beverage}

Microbiological assay of the beverages post 15 and 30 days of refrigeration was performed by standard spread plate method and incubated at $27 \pm 1^{\circ} \mathrm{C}$ in order to check for microbial growth. 
Statistical analysis was done by using CPCS1 software developed by Maths, Statistics and Physics Department, PAU, Ludhiana, India. One-way and Twoway ANOVA was applied and CD@5\% was calculated.

\section{Results and Discussion}

\section{Screening of Yeast Isolate}

Various physicochemical properties viz, TSS, ability to carbon dioxide content and low alcohol content served as criteria for the selection of yeast strain in the present studies. Yeast isolate from cheese whey (S10) was selected for further studies due to its ability to produce low alcohol $(0.8 \% \mathrm{v} / \mathrm{v})$ content and high carbonation (0.09 bar) as shown in Table 1 . Though other isolates (S9, S8, S5 and S3) were able to produce low alcohol content $(0.081,0.04,0.078$ and 0.09 respectively) but it was observed that compared to these isolates, S10 showed better carbonation. On the other hand, isolates S4 and S6 produced high carbon dioxide content (1.02 and 1.05 bar) but they produced higher alcohol content (1.8 and $1 \%$ ).

Table 1. Physicochemical properties of grape beverage fermented ( 3 days) by different isolates of yeast

\begin{tabular}{llllll}
\hline Sr. no. & $\begin{array}{l}\text { Isolate } \\
\text { used }\end{array}$ & $\begin{array}{l}\text { Alcohol } \\
\text { content }(\%)\end{array}$ & $\mathrm{CO}_{2}$ (bar) & $\mathrm{pH}$ & $\begin{array}{l}\text { TSS } \\
\left({ }^{\circ} \mathrm{B}\right)\end{array}$ \\
\hline 1 & $\mathrm{~S}-1$ & 0.80 & 0.08 & 3.40 & 14 \\
3 & $\mathrm{~S}-2$ & 0.15 & 0.02 & 3.30 & 14 \\
4 & $\mathrm{~S}-3$ & 0.09 & 0.08 & 3.40 & 14 \\
5 & $\mathrm{~S}-4$ & 1.80 & 1.02 & 4.30 & 12 \\
6 & $\mathrm{~S}-5$ & 0.08 & 0.05 & 3.70 & 11 \\
7 & $\mathrm{~S}-6$ & 1.00 & 1.05 & 4.10 & 12 \\
8 & $\mathrm{~S}-7$ & 0.12 & 0.02 & 3.50 & 14 \\
10 & $\mathrm{~S}-8$ & 0.04 & 0.05 & 4.20 & 13 \\
11 & $\mathrm{~S}-9$ & 0.08 & 0.04 & 2.60 & 11 \\
14 & $\mathrm{~S}-10$ & 0.08 & 0.09 & 3.80 & 15 \\
\hline
\end{tabular}

Table 2. Physicochemical properties of low alcoholic self carbonated beverage from grape juice and blends

\begin{tabular}{|c|c|c|c|c|c|}
\hline & \multirow[b]{2}{*}{ Parameters } & \multicolumn{3}{|l|}{ Time } & \multirow[b]{2}{*}{$\mathrm{CD}(5 \%)$} \\
\hline & & 3 days & 15 days & 30 days & \\
\hline \multirow{6}{*}{ Grape beverage } & $\mathrm{pH}$ & 3.93 & 3.50 & 3.180 & 0.06 \\
\hline & $\mathrm{TSS}^{0} \mathrm{~B}$ & 15.00 & 14.00 & 14.000 & 0.20 \\
\hline & $\mathrm{CO}_{2}$ (bar) & 0.09 & 0.10 & 0.110 & NS \\
\hline & Total acidity (\% citric acid) & 0.23 & 0.26 & 0.280 & NS \\
\hline & Brix- acid ratio $(\%)$ & 65.10 & 54.68 & 49.820 & 0.09 \\
\hline & Alcohol \% (v/v) & 0.08 & 0.09 & 0.100 & NS \\
\hline \multirow[t]{6}{*}{ Grape: Kinnow beverage } & $\mathrm{pH}$ & 4.00 & 3.74 & 3.270 & 0.04 \\
\hline & $\mathrm{TSS}^{0} \mathrm{~B}$ & 15.00 & 14.00 & 14.000 & 0.20 \\
\hline & $\mathrm{CO}_{2}$ (bar) & 0.08 & 0.11 & 0.130 & 0.02 \\
\hline & Total acidity (\% citric acid) & 0.20 & 0.30 & 0.345 & 0.04 \\
\hline & Brix- acid ratio $(\%)$ & 73.24 & 46.66 & 40.570 & 0.48 \\
\hline & Alcohol \% (v/v) & 0.08 & 0.10 & 0.140 & 0.02 \\
\hline \multirow[t]{6}{*}{ Grape: Pomegranate beverage } & $\mathrm{pH}$ & 3.87 & 3.64 & 3.080 & 0.06 \\
\hline & $\mathrm{TSS}^{0} \mathrm{~B}$ & 15.00 & 14.80 & 14.800 & NS \\
\hline & $\mathrm{CO}_{2}$ (bar) & 0.09 & 0.11 & 0.140 & 0.02 \\
\hline & Total acidity (\% citric acid) & 0.24 & 0.29 & 0.352 & 0.04 \\
\hline & Brix- acid ratio (\%) & 63.34 & 51.38 & 42.040 & 0.07 \\
\hline & Alcohol \% (v/v) & 0.06 & 0.07 & 0.100 & 0.02 \\
\hline
\end{tabular}

Table 3. Sensory evaluation of low-alcoholic self carbonated beverages produced from Vitis vinifera

\begin{tabular}{llll}
\hline Sensory attributes & Pure grape & Grape: Kinnow & Grape: Pomegranate \\
\hline Taste & 7.50 & 7.1 & 8.0 \\
Color & 7.60 & 6.9 & 7.9 \\
Aroma & 6.40 & 6.1 & 7.1 \\
Appearance & 7.40 & 6.8 & 7.5 \\
Mouth feel & 7.30 & 6.8 & 7.6 \\
Astringency & 7.00 & 6.7 & 7.4 \\
Flavor & 7.40 & 6.6 & 8.0 \\
Overall acceptability & 7.30 & 6.7 & 8.2 \\
Average score & 7.23 & 6.7 & 7.7 \\
\hline
\end{tabular}

*mean value of 10 replicates

Point hedonic scale. 9: like extremely, 8: like very much, 7: like moderately, 6: like slightly, 5: neither like nor dislike, 4: dislike slightly, 3: dislike moderately, 2: dislike very much 1: dislike extremely.

Blends (A)

$\begin{array}{cc}\text { F-ratio } & \text { CD }(5 \%) \\ 6.14 & 0.64 \\ 4.59 & 0.64 \\ 0.09 & \text { NS }\end{array}$

Blends*Attributes $(\mathrm{A} * \mathrm{~B})$ 


\section{Characterization of Yeasts Isolates}

\section{Morphological and Biochemical Characterization}

Colonies of S-10 exhibited viscous texture with off white colour, round, small and smooth with even margins and showed budding process and oval shaped cell under microscope after staining (Fig. 1a and b). Biochemical analysis showed that yeast isolate S-10 was able to ferment glucose, galactose and sucrose after 3 days of fermentation and gave negative results for urease, amylase and acid production test

\section{Molecular Characterization}

When subjected to molecular characterization, a single discrete PCR amplicon band of 750 bp was observed when resolved on Agarose Gel (Fig. 2). In gel image of 26S rDNA, lane 1 shows $26 \mathrm{~S}$ rDNA amplicon band and lane 2 shows DNA marker. Consensus sequence of $668 \mathrm{bp}$ rDNA gene was generated from forward and reverse sequence data using aligner software. The isolate was characterized as Saccharomyces cerevisiae strain NRRL Y-12632 by 26S rRNA gene (GenBank Accession Number: JQ689017.1) based on nucleotide homology and phylogenetic analysis. The evolutionary history (Fig. 3) was inferred using the Neighbor-Joining method (Saitou and Nei, 1987). The optimal tree with the sum of branch length $=1.27150290$ is shown. The evolutionary distances were computed using the Kimura 2-parameter method (Tamura et al., 2007) and are in the units of the number of base substitutions per site. All positions containing gaps and missing data were eliminated from the dataset. There were a total of 617 positions in the final dataset. Phylogenetic analyses were conducted in MEGA4 (Felsenstein, 1985).

\section{Physico Chemical Properties of Beverage}

Physico-chemical properties of pure grape, grape: Kinnow, grape: Pomegranate beverages were carried out after 3 days of fermentation and after 15 to 30 days under refrigerated conditions without addition of any preservatives (Table 2). The self-carbonation occurring during the fermentation process doesn't allow the growth of contaminating microorganism thus eliminating the use of any preservative. It was observed that the $\mathrm{pH}$, TSS $\left({ }^{\circ} \mathrm{B}\right)$ and brix acid ratio decreased with increase in preservation period. On the contrary, carbon dioxide content, total acidity (\%citric acid) and alcohol content increased till 30 days of refrigeration. This decrease in TSS can be attributed to the utilization of sugar by the microorganisms for metabolism; thereby producing by-products such has alcohol. An increase in carbon dioxide content and total acidity lead to a decrease in the $\mathrm{pH}$ of the beverage. Similar results were obtained by Sahota et al. (2010) who reported gradual increase in carbon dioxide content, total acidity ( $\%$ citric acid), alcohol $\%(\mathrm{v} / \mathrm{v})$ and gradual decrease in $\mathrm{pH}, \mathrm{TSS}\left({ }^{\circ} \mathrm{B}\right)$ and brix acid ratio of low alcoholic naturally carbonated blended guava and lemon beverage.

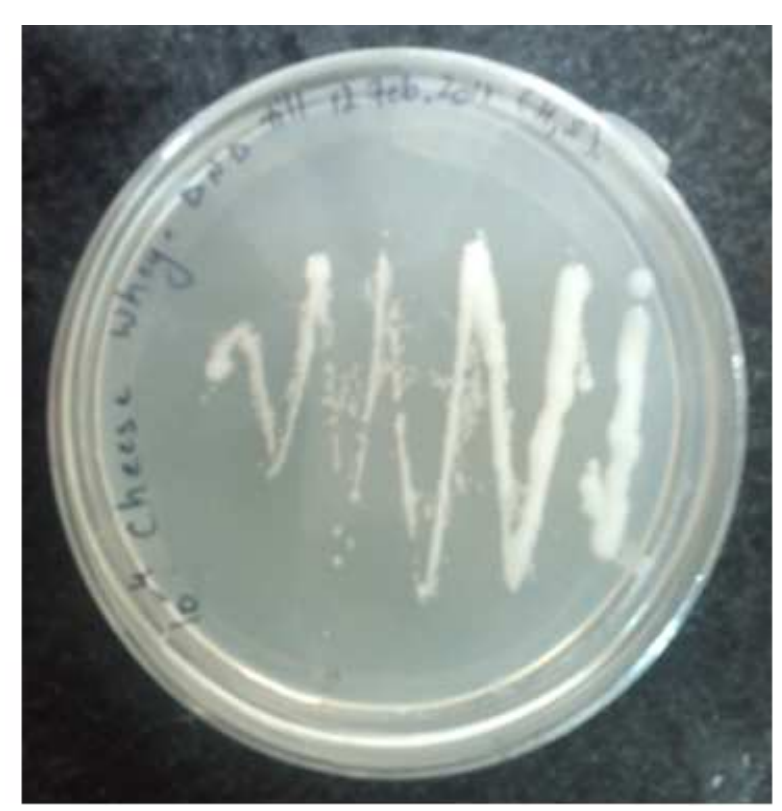

(a)

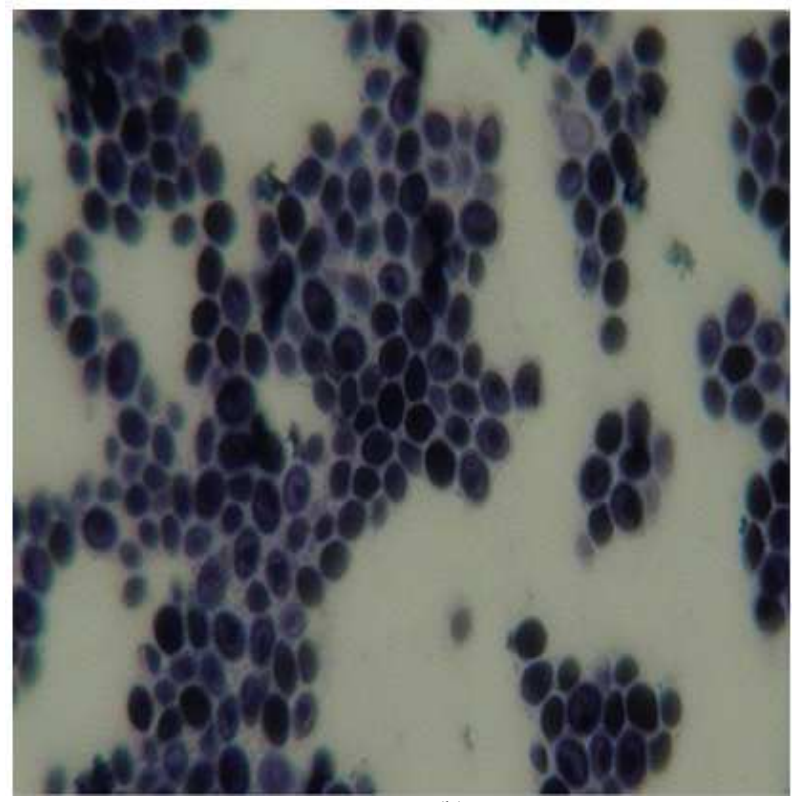

(b)

Fig. 1. (a) Yeast isolate S10 purified by streak plating method and (b) Microscopic view of yeast isolate S10 at $100 \mathrm{X}$ 


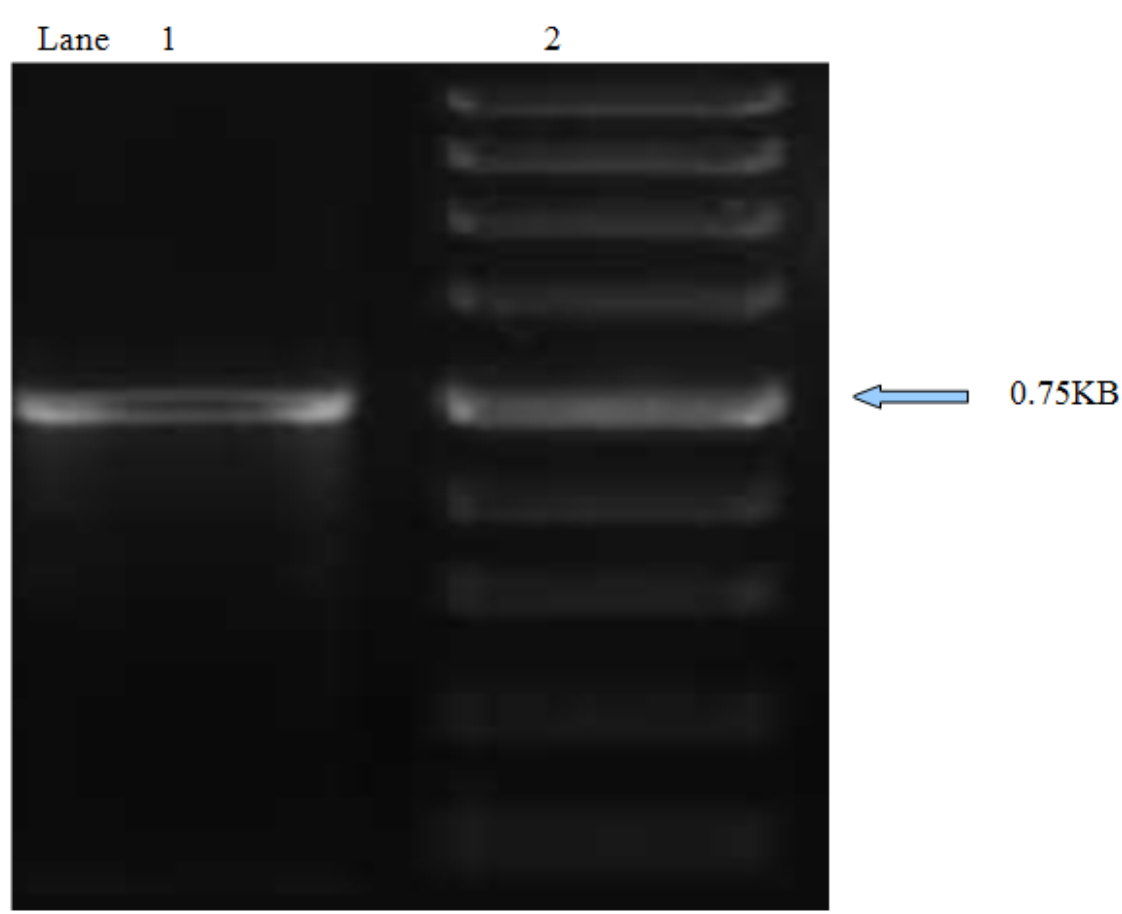

Fig. 2. Gel image of PCR amplicon band of $750 \mathrm{bp}$ of the yeast isolate S10

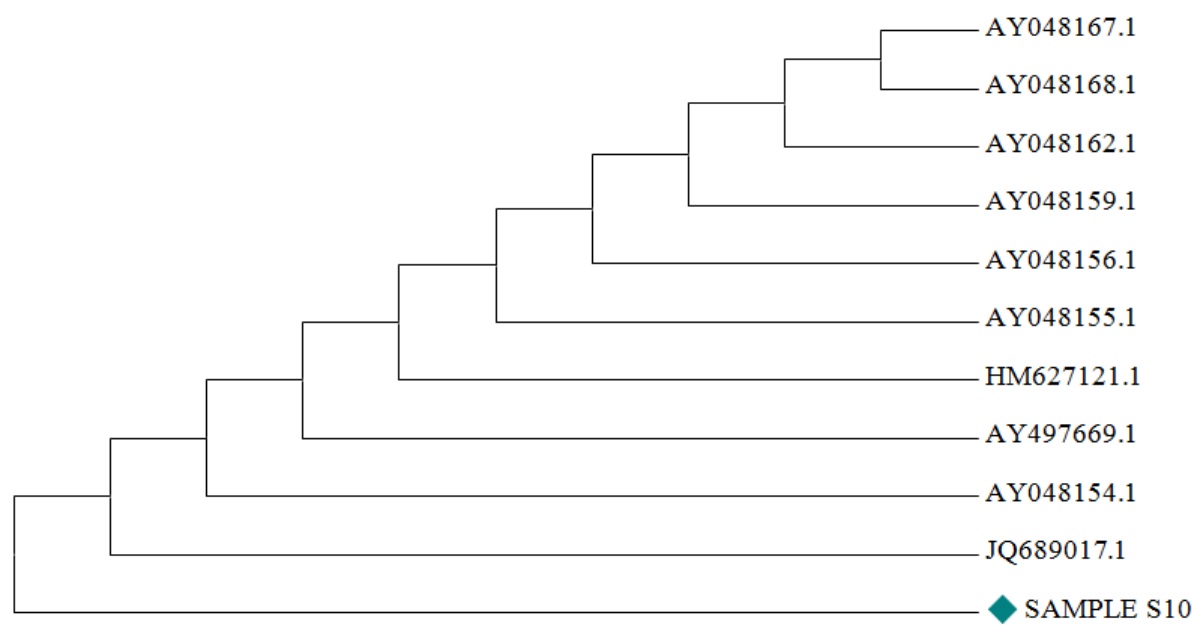

Fig. 3. Phylogenetic tree of the yeast isolate S10

\section{Sensory Evaluation}

Sensory evaluation was done on the basis of eight attributes that were taste, colour, aroma, appearance, mouth feel, astringency, flavour and overall acceptability by a group of 10 individuals after 15 and 30 days of refrigeration of beverage. According to nine-point hedonic scale, score was given to each beverage (pure grape, grape: Kinnow, grape: Pomegranate) (Table 3) on the basis of each attributes. Blended beverage of grape: Pomegranate with the ratio of (2:1) was most accepted out of all the three beverages with an average score of 7.7.

\section{Conclusion}

Market flooding of unhealthy, high calorie synthetic drinks has led to obesity especially in children. Governments and general public Worldwide have also shown concern regarding this growing problem. Therefore, alternative needs to be explored. The present has attempted to develop a technology for the production of non-alcoholic and self carbonated fruit based beverage using a yeast strain isolated from cheese whey. 


\section{Acknowledgement}

Authors are highly grateful to the School of Biotechnology and Biosciences, Lovely Professional University-Phagwara for their cooperation and encouragement.

\section{Funding Information}

This research received no grant from any funding agency in the public, commercial or not-for-profit sectors.

\section{Author's Contribution}

Heena Chilana: Participated in all experiments and contributed to the writing of the manuscript.

Sanju Arora: Participated in screening of yeast isolate and coordinated the data-analysis.

Robinka Khajuria: Participated in writing and proof reading of manuscript.

Loveleen Kaur: Designed the research plan and organized the study.

\section{Ethics}

The authors hereby declare that there is no conflict of interest.

\section{References}

Batac, K.N., J.I. Dumbrique, J.L. Gutierrez, J. Matienzo and M.P.J. Tabilin, 2012. Quantitative analysis of the alcohol content of various beers in the Philippines. Int. J. Chemical Environ. Eng., 3: 350-354.

Cunniff, P., 1999. Official Methods of Analysis. 16th Edn., AOAC International, Gaithersburg, pp: 1015.

Felsenstein. J, 1985. Confidence-limits on phylogeniesan approach using the bootstrap. Evolution, 39: 783-791

Fossi, B.T., F. Tavea, C. Jiwoua and R. Ndjouenkeu, 2009. Screening and phenotypic characterization of thermostable amylases producing yeasts and bacteria strains from some Cameroonian soils. African J. Microbiol. Res., 3: 504-514.

Ghinea, R., T. Vassu, I. Stoica, A.M. Tanase and O. Csutak, 2009. Preliminary taxonomic studies on yeast strains isolated from dairy products. J. Romanian Biotechnol. Lett., 14: 4170-4179.
Guilliermond, A., 2003. Culture Identification and Microbiology. 1st Edn., Watchmaker Publishing, New York, ISBN-10: 1929148143, pp: 448.

Jimoh, S.O., S.A. Ado, J.B. Ameh and C.M.Z. Whong, 2012. Characteristics and diversity of yeast in locally fermented beverages sold in Nigeria. World J. Eng. Appl. Sci., 2: 40-44.

Jooyandeh, H., 2013. Production of non-alcoholic fermented plum beverage. J. Scientific Res., 13: 836-843.

Kaur, L., R. Khajuria, S. Kaur and S. Rana, 2014. Production of low-alcoholic beverages from Citrus reticulata and Ananas comosus. Carpathian J. Food Sci. Technol., 6: 89-94.

Kolawole, O.M., R.M.O. Kayode and B. Akinduyo, 2007. Proximate and Microbial Analyses of Burukutu and Pito Produced in Ilorin, Nigeria. African J. Biotechnol., 6: 587-590.

Kurtzman, C.P., J.W. Fell, T. Boekhout and V. Robert, 2011. Methods for Isolation, Phenotypic Characterization and Maintenance of Yeasts. In: The Yeasts, a Taxonomic Study, Kurtzman, C.P., J.W. Fell and T. Boekhout (Eds.). Elsevier, Amsterdam, pp: 87-110.

Nile, S.H., S.H. Kim, E.Y. Ko and S.W. Park, 2013. Polyphenolic Contents and Antioxidant Properties of Different Grape ( $V$. vinifera, $V$. labrusca and V. hybrid) Cultivars. J. Biomed Res., 2013: 1-5. DOI: $10.1155 / 2013 / 718065$

Roberts, G.D, C.D. Horstmeier, G.A. Land and J.H. Foxworth, 1978. Rapid urea broth test for yeasts. J. Clin. Microbiol., 7: 584-588.

Saitou, N. and M. Nei, 1987. The neighbor-joining method: A new method for reconstructing phylogenetic trees. Mol. Biol. Evol., 4: 406-425

Sahota, P.P., A. Kaur and G. Pandove, 2010. Studies on preparation of low alcoholic naturally carbonated blended beverage from guava and lemon. Int. J. Food Safety, 12: 165-180.

Tamura, K., J. Dudley, M. Nei and S. Kumar, 2007. MEGA4: Molecular Evolutionary Genetics Analysis (MEGA) software version 4.0. Mol. Biol. Evol., 24: 1596-1599. 